\title{
The History and Future of Human Prospection
}

\author{
Adam Bulley \\ To appear in: Evolutionary Studies in Imaginative Culture
}

\begin{abstract}
In psychology, neuroscience, artificial intelligence and philosophy, "prediction" is widely recognized as central to cognition. Mental time travel into the future is the form of cognitive prediction ("prospection") most intimately connected to adaptive human functioning. It underpins explicit goal-setting, collaborative planning, and the pursuit of creative innovation. Theories focusing on prediction have a long intellectual history. Broadly construed, they offer perhaps the best opportunity yet for a global picture of neural and cognitive functioning. Exploiting this opportunity requires building bridges between prediction - as instantiated in perception or reinforcement learning - and fully-fledged mental time travel into the future. The surge of recent work on these topics indicates consensus about the promise of prospection for understanding diverse aspects of cognition, but subfields still lack theoretical synthesis.
\end{abstract}

Keywords: Prospection, foresight, prediction, mental time travel, evolution, imagination, culture, innovation, creativity, the self, free-will, consciousness

\section{Books under Review}

Seligman, Martin E. P., Peter Railton, Roy F. Baumeister, and Chandra Sripada. (2016) Homo Prospectus. Oxford: Oxford University Press. xiv, 400 pages. Hardcover $\$ 36.95$.

Michaelian, Kourken, Stanley B. Klein, and Karl K. Szpunar. (2016). Seeing the Future: Theoretical Perspectives on Future-Oriented Mental Time Travel. Oxford: Oxford University Press. viii, 464 pages. Hardcover $\$ 90$.

\section{Introduction: Artefacts of Prediction}

In the year 1900, a group of Greek sponge divers pulled an enigmatic artefact from the Aegean Sea: a lump of wood and metal that would only many decades later be identified as the world's first-known analogue computer (Freeth et al. 2006). The device, approximately two thousand years old and called the Antikythera mechanism, is of astonishing technological complexity (Marchant 2006). Analyses of the object in recent decades have revealed that it functioned as a predictive machine, used to represent the future of the heavens: the movement of the planets, position of the sun, and the phases of the moon. Once predicted, this celestial information was enlisted in the service of preparation, probably for timing agricultural and religious activities. Modern computer simulations suggest the device would have successfully predicted even recent eclipses, including the one whose shadow crossed the United States on August $21^{\text {st }} 2017$ (Wolfram 2017). The Antikythera mechanism tells us that for thousands of years humans have invested enormous effort in an attempt to predict and prepare; and, by extension, to engage in prospection - cognition that represents the future.

Ancient material evidence suggests that the history of human future thinking has a far more extensive lineage still. Consider a recently reported set of ground-edged hatchets from Northern Australia (Clarkson et al. 2017). At approximately 65,000 years old, they are the world's oldest-known. The tools were long-lived, and creating their highly polished edges required extensive abrasion with other rocks (Dickson 1980). They were also continually 
maintained, reshaped and reworked, with worn or damaged edges repaired so they could be used again when needed in the future (Hiscock et al. 2016). Further back into prehistory, perhaps some of the earliest evidence for prospective cognition in any Homo species comes in the form of Bifacial hand-axes (Hallos 2005), the oldest of which may be more than 1.76 million years old (Lepre et al. 2011). The complex production process of bifaces required more advanced planning than earlier tools (Wynn and Coolidge 2016). Moreover, they appear often to have been built in one location and then transported elsewhere for repeated use (Ambrose 2010).

An ancient stone tool like the biface might seem to have little in common with the Antikythera mechanism, other than that both are the functional end-products of human ingenuity and the spread of ideas. But both objects can also be thought of as extensions of a mind fundamentally geared towards the future. Only with behaviors enacted in the present moment (including the creation of powerful tools) can future successes be ensured and disasters averted, the crops kept alive; the predators warded off. The same logic applies to a great many of the artefacts of humanity fashioned over the eons to predict, prepare for, and confront possible futures: walls to stop potential invaders, writing to remember the debtor, seed-banks in case our planet begins to expire. These artefacts reflect a more general underlying fact: many of the mechanisms of human cognition are fundamentally futureoriented. The rise and growth of this prospective cognition has been a critical driver of our evolutionary success (Suddendorf and Corballis 2007). On this point, at least, most modern thinking about the science of human prospection converges.

The two books under review repeatedly propound the centrality of prospection to adaptive human functioning. Together, the books represent a cross-section of much of the relevant contemporary work, and readers will find much creative and fascinating research and theory in both. They are good companion pieces, together providing an exciting primer to the topic and a helpful resource on the array of emerging subfields. After surveying the history of research on prospection, I shall review these major subfields and discuss the major questions raised in the books: how do the mechanisms of "low-level" prediction relate to mental time travel $(M T T)$ ? What are the ultimate evolutionary origins of prospection? What are the applications to questions about metacognition, the self, free will, and consciousness? How does prospection as a capacity bear on creativity, innovation, and cultural change? Is it fair to conceptualise prospection as a paradigm-shift in our approach to the cognitive sciences (Kuhn 1962)?

\section{The Centrality of Prospection: A Historical Perspective}

The contributors to Homo Prospectus (HP) herald the science of prospection as a revelatory new approach for psychology. Seligman et al. tell us that psychologists, who have been long attached to the notion that the past and present determine human actions - as seen in behaviourism, psychoanalysis, and "most of cognitive psychology" (10) - have ignored the draw of the future. The authors assert that their re-conception, which places the future centerstage, is so radical in its implications that it calls for renaming our species "Homo Prospectus." The authors ask us to "take this name seriously" and underscore their request by making it the title of their book (10). I agree that the subject should be taken seriously, but the name would probably best be regarded as a rhetorical device. After all, "Homo Prospectus" joins a long list of other proposed names for our species from "Homo grammaticus" to "Homo technologicus":

https://en.wikipedia.org/wiki/Names_for_the_human_species_-all of which have gone unadopted since Linneaus called us Homo sapiens (1758). These names typically emphasize some particular aspect of human cognition or behavior that the author considers most 
imperative. "Prospection" has great promise as a research program but also risks becoming a buzz-word.

In being "drawn into the future" Seligman et al. —with an unintentional but appropriate irony - gloss over the intellectual history that scaffolds the contemporary science (Fukukura, Helzer, and Ferguson 2013). Prospection has been seriously discussed by thinkers ranging from the ancient Roman philosopher Seneca (65 AD) to the modern German philosopher Schopenhauer (1918). The seventeenth-century political philosopher Thomas Hobbes declared that "the opinions men have of the rewards and punishments which are to follow their actions are the causes that make and govern the will to those actions" (1640, $103)$.

In the opening pages of their introduction, Railton suggests an amendment to a famous statement by William James: "My thinking is first, and last, and always for my doing," to which Railton would add "and all of my doing extends forward in time, not backward." However, a more complete reading of James reveals his already extensive emphasis on the future. In Principles of Psychology I (1890), for instance, he argues that the fundamental function of the cerebral hemispheres of an animal is to simulate "remote objects" and "distant ends" that are not currently available to its senses. "[In] the cerebrum itself the same general distinction obtains, between considerations of the more immediate and considerations of the more remote. In all ages the man whose determinations are swayed by reference to the most distant ends has been held to possess the highest intelligence" (1980, 20).

In Principles of Psychology II, in a chapter dedicated to "the will," James deals at length with deliberation, anticipation, and voluntary action. Thus, as is often the case in psychology, James pre-empted or founded much of our current discussion, and it would be difficult to identify any significant hiatus in the interim. Other notable early thinkers on the topic include Helmholtz, Bergson, Kohler, Tolman, and Craik. Aside from his well-known work on 'cognitive maps' and latent learning (1948), Tolman wrote at length, earlier, about "purpose" as it related to psychological processing. He defined human "thought" as: "an internal presentation to the organism (on the basis of memory and association) of stimuli not actually present but which would be present, if some hypothesized action were carried out" (my emphasis) (Tolman 1920, 230). In his remarkably prescient "The Nature of Explanation" (1943), English philosopher Kenneth Craik paralleled this idea, introducing the concept of "mental models" and discussing their potential function as tools for organising behavior in the face of upcoming dangers and opportunities.

In the United States, the concept of "mental models" arose at around the same time as "cybernetics," a field that bought together control systems theory, information theory, neuroscience, anthropology and psychology to study control and communication in the animal and the machine - the subtitle of a seminal book by Norbert Wiener (1948).

Cyberneticists examined systems that act as if they have goals (The word cybernetic is

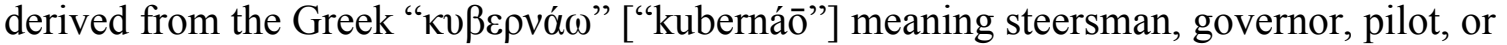
rudder.) In the 1940s and 1950s, cyberneticists placed a strong emphasis on prediction and feedback in the context of adaptive functioning. Those concepts eventually found a home in artificial intelligence research (Wiener 1948). A highly fruitful bi-directional relationship between the cognitive sciences and artificial intelligence followed, with search problems, planning, and goal-direction being productive areas of joint interest (reviewed in Russel and Norvig 2009).

Plans and the Structure of Behaviour, published in 1960 by George Miller and colleagues, applied cybernetics to psychology and became a founding text of the cognitive revolution (Miller, Galanter, and Pribram 1960). Miller et al. argued that complex step-wise planning might emerge through the operation and manipulation of internal mental models. 
Arguably, then, one of the hallmarks of the cognitive revolution in psychology was the introduction of "prospection" as expressed in the goal-directed control of behavior. Around the same time, social psychologist Walter Mischel had begun to investigate the capacity of young children to postpone their immediate gratification in pursuit of delayed rewards (Mischel 1961), though one should note that the concept of delayed gratification has parallel roots in sociology and economics (Straus 1962; Strotz 1955). In the 1970s, the study of "intertemporal choices" - of which Mischel's iconic marshmallow test can be considered one variant - was extended to pigeons (Ainslie 1974), and later to many other non-human animals (for reviews see Stevens 2010; Redshaw and Bulley 2018).

Prospection, forecasting and goal-directedness were central to much of Kahneman and Tversky's Nobel-prize winning research during the 1970s (e.g. Kahneman and Tversky 1977). At the same time, developmental psychologists were using linguistic analyses of young children's vocabulary to track "past" and "future" understanding (Harner 1975), and cognitive psychologists were beginning to study the mechanisms of prospective memory and delayed intention-setting (Meacham and Singer 1977). Learning theory was also being placed on a solid foundation of "expectation" (Rescorla and Wagner 1972), and neuroscientists had started to consider the role of the frontal lobes in executive functions and planning (Nauta 1971). Endel Tulving's framework for memory (1972) was particularly foundational at this time, and would soon be extended to encompass "future thinking" as well (Tulving 1985). In the 1980s and 1990s, philosophers offered detailed treatments of "intention" and "planning" (e.g. Bratman 1987). Meanwhile, economists continued to investigate the way prospective emotions guide decision-making (Frank, 1988), and clinical psychologists investigated their influence on affective disorders (Beck, Emery, and Greenberg 1985; MacLeod et al. 1997). Studies of patients with frontal lobe damage came to corroborate hypotheses about how the frontal lobe functions in adaptive goal-directed cognition (Ingvar 1985; Damasio 1994).

In 1997, Suddendorf and Corballis presented their seminal treatment of MTT, describing in detail its possible subcomponent processes. They also fleshed out the link between memory and foresight systems and discussed the evolutionary origins of MTT. Working in parallel, other scientists were investigating "low-level" sensory and behavioral neuroscience and artificial intelligence, developing arguments supporting the brain-basis of learning by prediction error. Those arguments led to theoretical models that identified prediction as a key aspect of sensory processing and deep learning (e.g. Dayan et al. 1995). Models like these, grounded in artificial intelligence research, found substantive empirical support in emerging neuroscientific investigations, including those delineating a key role for dopamine in reward prediction (Berridge and Robinson 1998; Schultz, Dayan, and Montague 1997). By the 2000s, the invention of neuroimaging led to a series of studies that served to corroborate the notion that memory and prospection should be thought of as two sides of the same coin (e.g. Okuda et al. 2003).

Since the turn of the millennium, a thriving research industry has emerged on the back of this rich history, much of which I cover in more detail below. Some major reviews have recently been published (Schacter, Benoit, and Szpunar 2017; Szpunar and Radvansky 2015), as well as a number of books and edited volumes including the two under direct consideration here (Suddendorf 2013b; Clark 2015; Macleod 2017; Oettingen, Sevincer, and Gollwitzer 2018; Michaelian 2016b; Bar 2011). This brief historical sketch should suffice to indicate that the significance of prospection has long been recognized. Accordingly, claims that the current surge of research amounts to a radical paradigm shift in psychology need to be taken with a grain of salt. Even so, it is undoubtedly true that we are witnessing a rapid growth in cross-disciplinary work on such questions. The two books under review here are testament to that growth. 
Prospection is a term sometimes reserved for "higher-order" cognition with a predictive component involving "thinking about the future" via explicit planning, foresight and imagination. These topics will be the focus of this review. However, the broader definition that includes all "predictive" processing in the brain and cognition touches a vast array of topics in the cognitive sciences. Some authors have suggested that there is a harmony at play here: that "prospection," broadly construed, might offer us an organizing principle for the brain and behavioral sciences (e.g. Clark 2015). The multiple fields of enquiry reviewed in the preceding historical sketch constitute different "levels" of analysis. Building conceptual linkages among those levels remains a major challenge.

\section{Traversing the Levels: From Prediction-Errors to MTT "Low-Level" Prediction}

In the opening chapters of Seeing the Future (STF), before they scale upwards, Railton and Shripada make a compelling and neurobiologically informed case for the operation and mechanisms of low-level prospection. Their account dovetails with a recent surge of interest related to "predictive processing" (Pezzulo 2016; Clark 2015; Clark 2013). Predictive processing and Bayesian approaches to brain function conceptualise neural processing as an ongoing comparison between new sensory input and existing internal probabilistic models of the causes of those sensory signals. In vision, for example, the brain is thought to strive toward a minimization of the prediction error that occurs as the eyes gather information from the outside world and compare that information with existing mental models. The interacting component parts of the visual system use this prediction error to update internal probabilistic models and thereby create increasingly useful cognitive representations (Friston 2009; Pezzulo, Rigoli, and Friston 2015; Dayan et al. 1995). In STF, Pezzulo (2016) surveys the relevant findings and current theoretical positions (see also Bubić, von Cramon, and Schubotz 2010). In the predictive processing account, the confluence of top-down predictions with bottom-up sensory input operates at the neural core of perception and action.

\section{“High-Level” Prediction}

Episodic foresight is the capacity to simulate future events, embed them in larger narratives, and then adjust present decision-making and behavior accordingly (Suddendorf and Moore 2011). Episodic foresight is not a unitary cognitive module; it requires a suite of interacting component capacities and operations. Neuroimaging while participants simulate the future has revealed a wealth of details about the possible mechanisms of episodic foresight, including its neural basis. Generally, imagining the future is associated with activation in the "default mode network," so-named because it is the activity also observed during taskunrelated rest. The involved brain regions include the medial temporal lobes, midline prefrontal cortex, and cingulate cortex (Buckner, Andrews-Hanna, and Schacter 2008;

Raichle et al. 2001; Smallwood et al. 2013; Bubić and Abraham 2014). Such findings suggest that people may often resort to imagining future possibilities when external task demands are low (Burgess, Dumontheil, and Gilbert 2007; Corballis 2013a; Smallwood and Schooler 2015; Spreng and Grady 2010).

\section{Building Bridges}

How much commonality is there between the "prediction" taking place at different levels of analysis in the cognitive sciences? Clark (2015) makes a rallying call for the utility of the predictive processing account:

Predictive processing offers an attractive "cognitive package deal" in which perception, understanding, dreaming, memory, and imagination all emerge as variant 
expressions of the same underlying mechanistic ploy-the ploy that meets incoming sensory data with matching top-down prediction. At the heart of the package lies the ability to use downwards connections to self-generate perception-like states. The very same "perceptual" machinery, driven from the top-down but insulated from entrainment by the driving sensory signal, then accounts for imagery and dreaming, and may pave the way for "mental time travel" as we assemble cues and contexts able to reconstruct the past and preconstruct the future (107).

This is a notion that receives support elsewhere (Pezzulo 2008). In an informative and wideranging chapter of STF, Pezzulo (2016) expresses his broad interpretation of the promise of predictive processing. Pezzulo's chapter includes an important discussion of findings of rodent hippocampus place cell activity that "replays" and "pre-plays" physical movement even when the animal is not moving. Interpreting these findings has proven contentious (Corballis 2013b; Gupta et al. 2010; Suddendorf 2013a; see also Pezzulo, Kemere, and Meer 2017). As Clark (2015) and Pezzulo (2016) acknowledge, achieving a global synthesis of prediction in the brain presents several problems. One is that "future-oriented" processing is highly multidimensional at every scale, especially the most "higher-order." Note, however, that there have been recent attempts to address even "high-level" concepts like "optimistic beliefs" (Sharot and Garrett 2016), and explicit "intertemporal choice" at the "low-level" of reinforcement learning (Lefebvre et al. 2017; Solway, Lohrenz, and Montague 2017). This problem extends to using different terminology for (perhaps?) the same things-such as the myriad names for episodic foresight/ episodic future thinking/ future-oriented MTT/ future simulations/ etc. Another problem is that theoretical and mathematical models of neural and cognitive mechanisms will only get us so far; we need to have an understanding that is not only neurobiologically plausible but also anchored in specific neural activity while simultaneously linking that activity to specific behavior. And a third problem: we should have a sense of how these mechanisms evolved, and why- notoriously difficult for complex cognitive processes (Tinbergen 1963). Given problems of this magnitude, one can understand the caution expressed in the final lines of the introduction to $S T F$ : "While parsimony is a laudable goal in theory construction, it may nevertheless turn out to be the case that the search for a common mechanism underlying the various forms of FMTT is futile" (14).

\section{The Relationship between Memory and Prospection}

Several authors have converged on the idea that memory is in essence forward-facing. This idea builds on early ideas of James (1890) about the source of "remote" sensations and also on concepts from cybernetics - for example, that in thinking systems "the prediction of the future of a message is done by some sort of operator on its past" (Wiener, 1950). Memory, in this view, is a system that empowers an organism to imagine, predict, or prepare for the future (Klein 2013; Suddendorf and Henry 2013; Suddendorf 2010; Szpunar and Tulving 2011; Suddendorf and Corballis 1997). Information accrued and stored through lived experience forms the building blocks for prospection. The ability to generate novel expectations about future events, especially in the form of narratives, relies in part on the recursive nesting of that information (Hassabis and Maguire 2009; Suddendorf and Corballis 1997; Schacter, Addis, and Buckner 2007).

MTT and semantic knowledge are deeply intertwined (Irish 2016; Szpunar 2010). As a "time-invariant repository of conceptual knowledge," semantic information provides a crucial "ingredient" in the construction of mental scenarios and may also guide the construction of diverse forms of future-oriented cognition (Irish, Piguet, and Hodges 2012; Irish et al. 2016). Indeed, researchers have suggested that semantic memory underpins episodic processing in both memory and prospection (Binder and Desai 2011; Irish and 
Piguet 2013; Tulving 1985) and that semantic knowledge is integrated into imagined possibilities during the "scenario building" process (Cheng et al., 2016). Szpunar et al. (2016) suggest that episodic and semantic formats of cognition are best thought of as lying on a gradient along which different "formats" of future thinking are expressed. One should recognize that there are also important differences between episodic foresight and episodic memory (Suddendorf 2010). For instance, they may differ in their reliance on "recombination" (Weiler et al. 2011) and also in brain activity (Bubić and Abraham 2014; Schacter, Benoit, and Szpunar 2017). See also the ongoing debates in philosophy about "continuism" vs. "discontinuism" as reviewed in STF (Perrin 2016; Michaelian 2016a).

\section{The Utility of Prospection (and Its Emergence)}

In seeking a comprehensive account of prospection, one may usefully invoke Tinbergen's four questions: about mechanisms, development, phylogeny and function (Tinbergen 1963; Scott-Phillips, Dickins, and West 2011). Several contributors to STF have made good headway on these questions. The development of prospective capacities has been discussed at length (Suddendorf 2017; Suddendorf and Redshaw 2013; Martin-Ordas, Atance, and Caza 2014; Atance and Mahy 2016; Gopnik et al. 2004). An emerging consensus affirms that the capacities come online piecemeal, with most available in rudimentary form by around age four. Comparing research on children's episodic future thinking to the research conducted with healthy adults, Atance \& Mahy (2016) argue that many assumptions we make about how adults imagine the future do not necessarily apply to non-verbal children. We cannot assume, for instance, that non-verbal children even imagine the future at all.

Many of the difficulties presented by studying prospection in non-verbal infants appear also in studying prospection in non-human animals. Comparative psychologists have had a long preoccupation with MTT, and "human uniqueness" has remained a major point of contention since MTT was originally articulated (Suddendorf and Corballis 1997; Tulving 2002). Emerging evidence suggests that animals are capable of considerably more sophisticated future-oriented behavior than was once thought possible (Osvath and MartinOrdas 2014; Thom and Clayton 2016; Redshaw and Bulley 2018; Martin-Ordas 2016). Explanations for these behaviors remain controversial, but in some cases the most parsimonious explanations attribute to animals mental representations of an anticipated future. (But see Thom \& Clayton in STF for an insightful critique of the principle of parsimony and "Morgan's Canon.")

Taking account of the way prospection enters into decision-making, most researchers agree that it has adaptive functionality (Gilbert and Wilson 2007). Its adaptive functionality is especially clear in its relationship with emotion. The emotional significance of a particular stimulus or event is an indicator of its biological value. Consequently, emotional reactions can serve as a common appraisal metric for environmental occurrences (Panksepp, 1998). Value, in this biological sense, relates directly to survival and reproduction. Episodic foresight enables the ascription of such value signals to imagined future events as well as to events that are directly perceived (Lin et al. 2015; Damasio 2009; Suddendorf and Busby 2005). People can thereby "evaluate" a future possibility long in advance by the way it makes them feel when they imagine it - a process known as "affective forecasting" (Wilson and Gilbert 2005).

Anticipated emotional reactions are commonly evoked in decision-making, but the role of foresight may be especially important in decisions with outcomes that play out only over time. Such decisions include intertemporal choices in which present and future consequences are in conflict (Benoit, Gilbert, and Burgess 2011; Peters and Büchel 2010; Bulley, Henry, and Suddendorf 2016; Jenkins and Hsu 2017). Boyer (2008) suggests that imagining future benefits may act as a motivational "brake" on the kind of impulsive 
decision-making that sacrifices long-term and cooperative effort to individual and immediate gratification. The brake works by providing some of the motivational salience of a future reward before it arises (Pezzulo and Rigoli 2011; Viganò 2017; Kurth-Nelson, Bickel, and Redish 2012; Hoerl and McCormack 2016). In line with this perspective, researchers increasingly see impaired foresight as a risk factor for addiction and a barrier to recovery (Noël, Jaafari, and Bechara 2017; Bickel et al. 2017; Terrett et al. 2017). (For an interesting discussion about the relative role of the semantic and episodic systems in modifying intertemporal choices, see Hoerl \& McCormack in STF [(2016)], Kwan et al. [2015], and Palombo et al. [2016]. The latter two sources also discuss the role of the medial temporal lobes among participants with amnesia.)

Evidence suggests that foresight is closely associated with the organization of personal goals and might thus be a particularly powerful tool in decision-making (e.g. Lehner and D'Argembeau 2016). Pursuit of these personal goals often involves "shaping one's future self" through deliberate practice (Suddendorf, Brinums, and Imuta 2016). In STF,

Suddendorf et al. argue that people can deliberately pursue specialization only by identifying a future skillset (and the path towards its acquirement), and that this deliberate pursuit goes some way toward explaining the powerful diversity of expertise that characterises humanity. Metacognition underpins such adaptive foresight in humans: one can only overcome one's cognitive limits by recognising those limits - recognizing, for instance that one lacks a certain skill, or that one's predictions could be wrong (Redshaw 2014; Redshaw and Bulley 2018).

\section{Impairments and Costs}

Life had overshot its target and blown itself apart. A species had been too heavily armed - its genius made it not only all-powerful in the external world, but equally dangerous to its own well-being.

(Zapffe 1933)

Human MTT has been described as "costly" because it probably requires a big, densely wired brain, which is slow to develop and metabolically "expensive." The empirical evidence about the "metabolic" costs of prospection is wanting, but these arguments can be regarded as extensions of the common idea that more "flexible" cognitive processes are harder to build than fixed action patterns of behavior designed to activate upon particular stimulus cues in the environment (see Dennett 1984). There is another potential cost to any highly complicated mechanism with many moving parts: it can break down in various ways. Research is now accumulating on changes in prospection in clinical subgroups including patients suffering from dementia, epilepsy, multiple sclerosis, schizophrenia, and normal aging (see Henry et al. 2016 for a special issue on the topic). It is difficult to ascertain precisely which situations are best viewed as "malfunctions" of the mechanisms, and which are better conceived of as either (i) by-products of other interacting capacities or (ii) extreme manifestations of normal individual-difference variance (Zietsch, de Candia, and Keller 2015; Nesse and Williams 1994)

Evolutionary costs and benefits to an organism are not the same as the costs and benefits to its subjective well-being. Peter Zapffe (1933) observes that the "genius" of human beings is a source also of great suffering. This may be true about the "genius" of prospection, which provides us not only with extraordinary powers of control, but also gives us the best seats in the house to mentally access futures we would perhaps rather not foresee: those that include ruin, suffering, and the death of loved ones or of ourselves. Varki (2009) suggests that for mechanisms allowing this mental access to have evolved at all, simultaneous systems for self-deception would have been required to offset the negative consequences such 
existential dread would engender for adaptive behavior (see also von Hippel and Trivers 2011). Whether or not this is true, the suffering brought about by prospection is most obvious in the context of depression and anxiety, where negatively valenced future simulations are common. Of depression, Roepke and Seligman in STF declare that "dysfunctional prospection creates depression" (2015), though this is perhaps a premature conclusion given the correlational nature of the majority of the research (reviewed in Miloyan, Pachana, and Suddendorf 2014). A long-running research program by MacLeod and colleagues has suggested a more complex relationship between prospection, well-being and mental health (MacLeod 2016; MacLeod et al. 1997). Being able to "auto-cue" future threat events and narratives without any immediate sensory threat cues is a powerful adaptive tool for managing potential dangers (Miloyan, Bulley, and Suddendorf 2018), but it is also a central feature of clinical anxiety (Bulley, Henry, and Suddendorf 2017; Miloyan, Pachana, and Suddendorf 2014). As with depression, it is still unclear what causal role negative prospection may play in anxiety.

\section{Philosophical Implications \\ The Self and the Future}

Cognitive scientists and philosophers have begun to address the difficult problem of how the current "self" relates to the future or possible "selves" into which it may transition (Hershfield et al. 2011; Markus and Nurius 1986; Manning 2016). Empirical advances in the form of "thought-sampling" and studies of selfhood in amnesic patients have begun to trace out what a science of "the self" integrated with prospection would look like. In STF, D'Argembeau (2016) argues that much of our MTT is organised around "self-defining experiences" in memory and "self-defining future projections" in foresight. Research on personal semantic memory (Renoult et al. 2012) and semantic conceptions of the self suggest that multiple interacting systems are at play in its construction (Conway, Loveday, and Cole 2016; Klein and Gangi 2010).

Predictive processing accounts of the self are often tied up with notions of embodiment and action. "Active" and "interoceptive" inference paint a picture of reciprocal feedback between internal predictive models and stimuli in the environment or the body (e.g. from the viscera), respectively (Clark 2008). Because the organism continually engages the world via motor planning and behavior to select the stimuli that will connect with its sensors, it can perform actions that reduce prediction errors by bringing sensory states in line with expectations (Pezzulo 2012; Seth 2014; Friston 2009). Newly accrued evidence can thereby update the initial models and thus change future learning and action (Friston et al. 2017). This process of "active inference" inexorably links the organism and the environment. Related "enactivist" or "embodiment" perspectives raise interesting questions about where the boundaries of the self would best be drawn. Again, this idea traces its lineage to cybernetics:

Consider a tree and a man and an axe. We observe that the axe flies through the air and makes certain sorts of gashes in a pre-existing cut in the side of the tree. If now we want to explain this set of phenomena, we shall be concerned with differences in the cut of the face of the tree, differences in the retina of the man, differences in his central nervous system, differences in his efferent neural messages, differences in the behaviour of his muscles, differences in how the axe flies, to the differences which the axe then makes in the face of the tree. Our explanation (for certain purposes) will go round and round that circuit. In principle, if you want to explain or understand anything in human behaviour, you are always dealing with total circuits, completed circuits. This is the elementary cybernetic thought." (Bateson 1972, 465) 


\section{Prospection and Free-Will}

In $S T F$, Seligman et al. underscore the importance of having an "option set" for free-will. Recent experiments have shown it may be possible to increase the cognitive "option set" and change the perceived emotionality and plausibility of those options (Jing, Madore, and Schacter 2017). However, Seligman et al. disavow any intention of engaging the metaphysical debate about free will. The reader is then left to wonder why "free will" as a philosophical question enters the discussion at all. As the authors acknowledge, nothing about "prospection" necessarily hints at reframing the free-will debate in metaphysical terms. (Prospective cognition all takes place "in the present," as a result of whatever processes in the universe happen to engender them.) Metaphysics aside, the prospection approach is clearly useful in the psychology of volition-for instance in understanding the psychological determinants of choices when options are pitted against one another and people must choose between them (Berns, Laibson, and Loewenstein 2007; Haggard 2008).

\section{The King of the Questions in the Cognitive Sciences}

Questions about consciousness have long been central to the study of prospection. The famous distinction made by Endel Tulving between episodic and semantic forms of declarative memory placed a special kind of conscious awareness center-stage. Episodic memory is defined by "autonoetic" ("self-knowing") consciousness that involves the firstperson subjective experience of previously lived events. Semantic memory represents "noetic" (knowing) consciousness that does not require any explicit mental simulation (see also Szpunar and Tulving 2011). The subjectivity of autonoesis has produced much hand wringing, especially in pre-verbal developmental and comparative psychology, where selfreport is impossible, but the scientific opacity of autonoesis has not stopped some interesting speculations about the mechanistic underpinnings of conscious prospection. In $S T F$, Sripada (2016) invokes conscious broadcasting to explain the way episodic memory states disseminate to neocortical "deep learning mechanisms," which use them for foresight. This explanation is not wholly satisfying. There is no compelling reason memory states would need to be distributed via conscious means. Baumeister (2016a) suggests that the conscious experience of feelings might serve a role in affective "evaluations" that are useful in learning and prospection rather than in immediate action. This is an interesting idea, but it too is speculative.

In STF, Martin-Ordas (2016) takes aim at the issue of consciousness in non-human animals. She argues that while we cannot necessarily prove that non-human animals have subjective experiences, we cannot rule out the possibility, either. Klein reminds us that we cannot define our way out of this problem: "If our available techniques are unable to capture this core feature of memory [and foresight], then so much worse for our techniques" (2014, $23)$. For the time being, we seem to have reached an impasse on this question. In many projects on which scientists of prospection are engaged, putting consciousness to one side seems to be a useful strategy. Nonetheless, the scientific study of consciousness has seen a herculean surge of research effort over the last three decades (Dennett 2017; Tononi 2004; Koch and Tsuchiya 2007; Chalmers 1995; Crick and Koch 1990; Edelman 1992; Dehaene and Naccache 2001). It remains to be seen what potentially fruitful insights the science of prospection will provide.

\section{Prospection, Invention, Culture and Creativity}

Metacognition allows for the invention of particular kinds of tools that allow us to "offload cognition" into the environment, for instance by writing things down (Risko and Gilbert 2016). The writing paper (or computer) and its symbols can be considered as part of the extended cognitive system - and in some respects as part of the organism's "extended 
phenotype" (Clark 2008; Dawkins 1982). The creativity that builds these inventions is fundamentally imaginative and prospective (Abraham 2016; Dong, Collier-Baker, and Suddendorf 2015). Any attempt to generate possible alternatives (e.g. novel 'uses' for things) involves some flexible re-combinatorial thought. Foresight also means humans can imagine the functionality and aesthetics of potential creations before any physical manufacture begins. Whether a solution to a problem is "figured out" or merely stumbled upon by accident, solutions can be recognized as having future utility (von Hippel \& Suddendorf, under review). The new discovery can be spread through social networks, amended, changed, borrowed, sold, or stolen, all elements in the process of "cultural evolution."

Corballis and Suddendorf argue that language may have evolved, at least in part, because it enables the sharing of mental time travels into the past and future (Corballis and Suddendorf 2007). Consider the long-recognized connections between imagination, MTT and storytelling (McBride 2012; Abraham 2016; Boyer and Parren 2015; Mahr and Csibra 2017). With simulations of the future come insights about what it might hold. When pooled, those insights can be improved in accuracy or utility. Humans share, discuss and create collaborative plans and socially construct concepts about the future, including ideas about what is worth striving for (Baumeister 2016b). When coupled with a powerful desire to "connect our minds together," the capacity for simulating the future becomes starkly more potent as an evolutionary weapon in the struggle for survival and reproduction (Suddendorf 2013b; von Hippel 2018).

The implications of this perspective for cultural phenomena are intuitively suggestive. Think of the importance of prospection in legal, religious, and financial systems. Nonetheless, the precise role of episodic foresight in cultural evolution remains somewhat opaque (Mesoudi 2007). Cognitive systems for the regulation of collaborative foresight, including those subserving morality, may have piggybacked on language-enabled MTT. Recent studies have shown that imagining future pro-social actions can encourage more altruistic behavior (e.g. Gaesser and Schacter 2014): more evidence that foresight might reduce the temporal discounting that would otherwise encourage the pursuit of "selfish" opportunities (see also Hill et al. 2017; Boyer 2008; O'Connell, Christakou, and Chakrabarti 2015). Furthermore, as underscored in $S T F$, moral attitudes and judgements may also track prior transgressions and cooperation so that efficient predictions can be made about the likely future cooperativeness of conspecifics (Railton 2016).

\section{Conclusion}

The science of prospection, broadly construed, may offer the best opportunity yet devised to find an overarching paradigmatic account of cognition. Over the past 100 years, intense research on the instantiation of prediction, from sensory perception to MTT, has built the foundations for this science. Those foundations have been laid in multiple fields: psychology, neuroscience, artificial intelligence and philosophy. In coming years, researchers may successfully bridge the levels of analysis in these diverse fields. The surge of recent interest in these questions suggests a growing consensus that prospection, in its many guises, has a central role in neural and cognitive functioning. In its most "higher-order" form, prospection manifests as MTT into the future, mind-wandering, subjective temporality, creativity, and innovation. Whether or not these phenomena can be understood as manifestations of some underlying general mechanism remains to be seen.

Prospection has been billed as offering a framework for big questions about the self, free will, and consciousness. Such high claims invite sceptical caution. If prospection is to serve as an organizing principle for the cognitive sciences, we will need to recognize its limitations. Despite these caveats, what is emerging is a distinct and valuable conception of the human mind as an embodied predictive system with complex cultural and material 
scaffolding. Objects like the Antikythera mechanism tell us that humans have obsessed over the future for thousands of years. The evolutionary lineage of this obsession probably runs back into the millions. Ultimately, we will continue using prospection to survey possible futures, to shape ourselves, and to create pathways to bring about the futures we desire.

\section{Acknowledgements}

I would like to thank Thomas Suddendorf, Beyon Miloyan, David Bulley, Jonathan Redshaw, Muireann Irish, Karl Szpunar, Giovanni Pezzulo and Joseph Carroll for their helpful comments on earlier drafts of this paper.

\section{Works cited}

Abraham, Anna. 2016. “The Imaginative Mind.” Human Brain Mapping 37 (11): 4197-4211. doi: $10.1002 / \mathrm{hbm} .23300$.

Ainslie, G. W. 1974. "Impulse Control in Pigeons." Journal of the Experimental Analysis of Behavior 21 (3): 485-89. doi:10.1901/jeab.1974.21-485.

Ambrose, S. H. 2010. "Coevolution of Composite-Tool Technology, Constructive Memory, and Language." Current Anthropology 51 (S1): S135-47. doi:10.1086/650296.

Atance, Cristina. M., and Caitlin E V Mahy. 2016. "Episodic Future Thinking in Children: Methodological and Theoretical Approaches." In Seeing the Future: Theoretical Perspectives on Future-Oriented Mental Time Travel, edited by K. Michaelian, Stanley B. Klein, and Karl K. Szpunar, 367. New York: Oxford University Press. doi:10.1093/acprof:oso/9780190241537.003.0018.

Bar, Moshe. 2011. Predictions in the Brain: Using Our Past to Generate a Future. Oxford University Press. doi:10.1093/acprof:oso/9780195395518.001.0001.

Baumeister, Roy F. 2016a. "Emotions: How the Future Feels (and Could Feel)." In Homo Prospectus. Oxford University Press.

Baumeister, Roy F. 2016b. "Collective Prospection: The Social Construction of the Future." In Homo Prospectus. Oxford University Press.

Beck, Aaron T, Gary Emery, and Ruth L. Greenberg. 1985. Anxiety Disorders and Phobias: A Cognitive Perspective. Basic Books.

Benoit, Roland G., Sam J. Gilbert, and Paul W. Burgess. 2011. "A Neural Mechanism Mediating the Impact of Episodic Prospection on Farsighted Decisions." The Journal of Neuroscience 31 (18): 6771-79. doi:10.1523/jneurosci.6559-10.2011.

Berns, Gregory S., David Laibson, and George Loewenstein. 2007. "Intertemporal Choice toward an Integrative Framework." Trends in Cognitive Sciences 11 (11): 482-88. doi:10.1016/j.tics.2007.08.011.

Berridge, K. C, and T. E. Robinson. 1998. "What Is the Role of Dopamine in Reward: Hedonic Impact, Reward Learning, or Incentive Salience?" Brain Res Brain Res Rev 28 (3): 309-69. doi:10.1016/S0165-0173(98)00019-8.

Bickel, Warren K., Alexandra M. Mellis, Sarah E. Snider, Liqa N. Athamneh, Jeffrey S. Stein, and Derek A. Pope. 2017. "21st Century Neurobehavioral Theories of Decision Making in Addiction: Review and Evaluation." Pharmacology Biochemistry and Behavior. doi:10.1016/j.pbb.2017.09.009.

Binder, Jeffrey R., and Rutvik H. Desai. 2011. "The Neurobiology of Semantic Memory." Trends in Cognitive Sciences 15 (11): 527-36. doi:10.1016/j.tics.2011.10.001.

Boyer, Pascal. 2008. "Evolutionary Economics of Mental Time Travel?" Trends in Cognitive Sciences 12 (6): 219-24. doi:10.1016/j.tics.2008.03.003.

Boyer, Pascal, and Nora Parren. 2015. "Threat-Related Information Suggests Competence: A Possible Factor in the Spread of Rumors." PloS One 10 (6): e0128421. doi:10.1371/journal.pone.0128421. 
Bratman, Michael E. 1987. Intention, Plans, and Practical Reason. Cambridge: Cambridge University Press.

Bubić, Andreja, and Anna Abraham. 2014. "Neurocognitive Bases of Future Oriented Cognition." Review of Psychology 21 (1): 3-15.

Bubić, Andreja, D. Yves von Cramon, and Ricarda I Schubotz. 2010. "Prediction, Cognition and the Brain." Frontiers in Human Neuroscience 4 (March): 25. doi:10.3389/fnhum.2010.00025.

Buckner, Randy L., Jessica R. Andrews-Hanna, and Daniel L. Schacter. 2008. "The Brain's Default Network: Anatomy, Function, and Relevance to Disease." Annals of the New York Academy of Sciences 1124: 1-38. doi:10.1196/annals.1440.011.

Bulley, Adam, Julie D. Henry, and Thomas Suddendorf. 2017. "Thinking about Threats: Memory and Prospection in Human Threat Management." Consciousness and Cognition 49: 53-69. doi:10.1016/j.concog.2017.01.005.

Bulley, Adam, Julie Henry, and Thomas Suddendorf. 2016. "Prospection and the Present Moment: The Role of Episodic Foresight in Intertemporal Choices between Immediate and Delayed Rewards." Review of General Psychology 20 (1): 29-47. doi:10.1037/gpr0000061.

Burgess, Paul W., Iroise Dumontheil, and Sam J. Gilbert. 2007. "The Gateway Hypothesis of Rostral Prefrontal Cortex (Area 10) Function." Trends in Cognitive Sciences 11 (7): 290-98. doi:10.1016/j.tics.2007.05.004.

Chalmers, David J. 1995. "Facing Up to the Problem of Consciousness." Journal of Conscious Studies 2 (3): 200-219. doi:10.1093/acprof.

Clark, Andy. 2008. Supersizing the Mind: Embodiment, Action, and Cognitive Extension. Oxford University Press. doi:10.1093/acprof:oso/9780195333213.001.0001.

_ 2013. "Whatever next? Predictive Brains, Situated Agents, and the Future of Cognitive Science.” Behavioral and Brain Sciences 36 (3): 181-204. doi:10.1017/S0140525X12000477.

- 2015. Surfing Uncertainty: Prediction, Action, and the Embodied Mind. Oxford University Press.

Clarkson, Chris, Zenobia Jacobs, Ben Marwick, Richard Fullagar, Lynley Wallis, Mike Smith, Richard G. Roberts, et al. 2017. "Human Occupation of Northern Australia by 65,000 Years Ago." Nature 547 (7663): 306-10. doi:10.1038/nature22968.

Conway, Martin A., Catherine Loveday, and Scott N. Cole. 2016. "The Rememberingimagining System.” Memory Studies 9 (3): 256-65. doi:10.1177/1750698016645231.

Corballis, Michael C. 2013a. "Wandering Tales: Evolutionary Origins of Mental Time Travel and Language." Frontiers in Psychology 4: 485. doi:10.3389/fpsyg.2013.00485.

Corballis, Michael C. 2013b. "Mental Time Travel: A Case for Evolutionary Continuity." Trends in Cognitive Sciences 17 (1): 5-6. doi:10.1016/j.tics.2012.10.009.

Corballis, Michael C., and Thomas Suddendorf. 2007. "Memory, Time and Language." In What Makes Us Human?, edited by C. Pasternak, 17-36. Oneworld.

Crick, Francis, and Christof Koch. 1990. "Towards a Neurobiological Theory of Consciousness." In Seminars in the Neurosciences, 2:263-75. Saunders Scientific Publications.

D'Argembeau, Arnaud. 2016. "The Role of Personal Goals in Future-Oriented Mental Time Travel." In Seeing the Future: Theoretical Perspectives on Future-Oriented Mental Time Travel, edited by K. Michaelian, Stanley B. Klein, and Karl K. Szpunar. New York: Oxford University Press. doi:10.1093/acprof:oso/9780190241537.003.0010.

Damasio, Antonio R. 1994. Descartes' Error: Emotion, Reason, and the Human Brain. Putnam Publishing.

—. 2009. "Neuroscience and the Emergence of Neuroeconomics." Neuroeconomics: 
Decision Making and the Brain, 209-14. doi:10.1016/B978-0-12-374176-9.00014-2. Dawkins, Richard. 1982. The Extended Phenotype: The Long Reach of the Gene. Oxford University Press.

Dayan, Peter, Geoffrey E. Hinton, Radford M. Neal, and Richard S. Zemel. 1995. "The Helmholtz Machine.” Neural Computation 7 (5): 889-904. doi:10.1162/neco.1995.7.5.889.

Dehaene, Stanislas, and Lionel Naccache. 2001. "Towards a Cognitive Neuroscience of Consciousness: Basic Evidence and a Workspace Framework." Cognition 79 (1-2): 137. doi:10.1016/S0010-0277(00)00123-2.

Dennett, Daniel C. 1984. Elbow Room: The Varieties of Free Will Worth Wanting. MIT Press.

- 2017. From Bacteria to Bach and Back: The Evolution of Minds. WW Norton \& Company.

Dickson, Francis Percy. 1980. “Of Grinding Grooves.” Archaeology in Oceania 15 (3): 15761.

Dong, Andy, Emma Collier-Baker, and Thomas Suddendorf. 2015. "Building Blocks of Human Design Thinking in Animals." International Journal of Design Creativity and Innovation 349 (February): 1-15. doi:10.1080/21650349.2015.1011700.

Edelman, Gerald M. 1992. Bright Air, Brilliant Fire: On the Matter of the Mind. New York: Basic Books.

Freeth, T., Y. Bitsakis, X. Moussas, J. H. Seiradakis, A. Tselikas, H. Mangou, M. Zafeiropoulou, et al. 2006. "Decoding the Ancient Greek Astronomical Calculator Known as the Antikythera Mechanism." Nature 444 (7119): 587-91. doi:10.1038/nature05357.

Friston, Karl. 2009. "The Free-Energy Principle: A Rough Guide to the Brain?" Trends in Cognitive Sciences 13 (7): 293-301. doi:10.1016/j.tics.2009.04.005.

Friston, Karl, Thomas FitzGerald, Francesco Rigoli, Philipp Schwartenbeck, and Giovanni Pezzulo. 2017. "Active Inference: A Process Theory." Neural Computation 29 (1): 149. doi:10.1162/NECO_a_00912.

Fukukura, Jun, Erik G. Helzer, and Melissa J Ferguson. 2013. "Prospection by Any Other Name? A Response to Seligman et Al. (2013).” Perspectives on Psychological Science 8 (2013): 146-50. doi:10.1177/1745691612474320.

Gaesser, Brendan, and Daniel L. Schacter. 2014. "Episodic Simulation and Episodic Memory Can Increase Intentions to Help Others." Proceedings of the National Academy of Sciences 111 (12): 4415-20. doi:10.1073/pnas.1402461111.

Gilbert, Daniel T., and Timothy D. Wilson. 2007. "Prospection : Experiencing the Future." Science 317 (5843): 1351-54. doi:10.1126/science.1144161.

Gopnik, Alison, Clark Glymour, David M. Sobel, Laura E. Schulz, Tamar Kushnir, and David Danks. 2004. "A Theory of Causal Learning in Children: Causal Maps and Bayes Nets." Psychological Review 111 (1): 3. doi:10.1037/0033-295X.111.1.3.

Gupta, Anoopum S., Matthijs A. A. van der Meer, David S. Touretzky, and A. David Redish. 2010. "Hippocampal Replay Is Not a Simple Function of Experience." Neuron 65 (5): 695-705. doi:10.1016/j.neuron.2010.01.034.

Haggard, Patrick. 2008. "Human Volition: Towards a Neuroscience of Will." Nature Reviews Neuroscience 9 (12): 934-46. doi:10.1038/nrn2497.

Hallos, Jane. 2005. "'15 Minutes of Fame': Exploring the Temporal Dimension of Middle Pleistocene Lithic Technology." Journal of Human Evolution 49 (2): 155-79. doi:10.1016/j.jhevol.2005.03.002.

Harner, Lorraine. 1975. "Yesterday and Tomorrow: Development of Early Understanding of the Terms." Developmental Psychology 11 (6): 864. 
Hassabis, Demis, and Eleanor A. Maguire. 2009. "The Construction System of the Brain." Philosophical Transactions: Biological Sciences 364 (1521). The Royal Society: 126371. doi:10.2307/40485894.

Henry, Julie D., Donna Rose Addis, Thomas Suddendorf, and Peter G. Rendell. 2016. "Introduction to the Special Issue: Prospection Difficulties in Clinical Populations." British Journal of Clinical Psychology 55 (1): 1-3. doi:10.1111/bjc.12108.

Hershfield, Hal E., Daniel G. Goldstein, William F. Sharpe, Jesse Fox, Leo Yeykelis, Laura L. Carstensen, and Jeremy N. Bailenson. 2011. "Increasing Saving Behavior Through Age-Progressed Renderings of the Future Self." JMR, Journal of Marketing Research 48 (November): S23-37. doi:10.1509/jmkr.48.SPL.S23.

Hill, Paul F., Richard Yi, R. Nathan Spreng, and Rachel A. Diana. 2017. "Neural Congruence between Intertemporal and Interpersonal Self-Control: Evidence from Delay and Social Discounting." NeuroImage 162 (September): 186-98. doi:10.1016/j.neuroimage.2017.08.071.

Hippel, William von. 2018. The Social Leap. New York: Harper Collins.

Hippel, William von., and R. Trivers. 2011. "The Evolution and Psychology of SelfDeception.” Behav Brain Sci 34 (1): 1-56. doi:10.1017/S0140525X10001354.

Hiscock, Peter, Sue O'Connor, Jane Balme, and Tim Maloney. 2016. "World's Earliest Ground-Edge Axe Production Coincides with Human Colonisation of Australia." Australian Archaeology 82 (2): 2-11. doi:10.1080/03122417.2016.1164379.

Hoerl, Christoph, and Teresa McCormack. 2016. "Making Decisions about the Future: Regret and the Cognitive Function of Episodic Memory." In Seeing the Future: Theoretical Perspectives on Future-Oriented Mental Time Travel, edited by K. Michaelian, Stanley B. Klein, and Karl K. Szpunar, 241-66. New York: Oxford University Press.

Ingvar, D. H. 1985. "'Memory of the Future': An Essay on the Temporal Organization of Conscious Awareness." Human Neurobiology 4 (3): 127-36.

Irish, Muireann. 2016. "Semantic Memory as the Essential Scaffold for Future-Oriented Mental Time Travel." In Seeing the Future: Theoretical Perspectives on FutureOriented Mental Time Travel, edited by K. Michaelian, Stanley B. Klein, and Karl K. Szpunar, 389-408. New York: Oxford University Press Oxford.

Irish, Muireann, Nadine Eyre, Nadene Dermody, Claire O’Callaghan, John R. Hodges, Michael Hornberger, and Olivier Piguet. 2016. "Neural Substrates of Semantic Prospection - Evidence from the Dementias." Frontiers in Behavioral Neuroscience 10 (May): 96. doi:10.3389/fnbeh.2016.00096.

Irish, Muireann, and Olivier Piguet. 2013. "The Pivotal Role of Semantic Memory in Remembering the Past and Imagining the Future." Front Behav Neurosci 7: 27. doi:10.3389/fnbeh.2013.00027.

Irish, Muireann, Olivier Piguet, and John R. Hodges. 2012. "Self-Projection and the Default Network in Frontotemporal Dementia." Nature Reviews Neurology 8 (3): 152-61. doi:10.1038/nrneurol.2012.11.

Jenkins, Adrianna C., and Ming Hsu. 2017. "Dissociable Contributions of Imagination and Willpower to the Malleability of Human Patience." Psychological Science 28 (7): 894906. doi:10.1177/0956797617698133.

Jing, Helen G., Kevin P. Madore, and Daniel L. Schacter. 2017. "Preparing for What Might Happen: An Episodic Specificity Induction Impacts the Generation of Alternative Future Events.” Cognition 169 (March): 118-28. doi:10.1016/j.cognition.2017.08.010.

Kahneman, Daniel, and Amos Tversky. 1977. "Intuitive Prediction: Biases and Corrective Procedures." In Judgement under Uncertainty: Heuristics and Biases. Cambridge University Press. doi:10.1017/CBO9780511809477.031.

Klein, Stanley B. 2014. "What Memory Is.” Wiley Interdisciplinary Reviews. Cognitive 
Science 6 (1): 1-38. doi:10.1002/wcs.1333.

Klein, Stanley B. 2013. "The Temporal Orientation of Memory: It's Time for a Change of Direction." Journal of Applied Research in Memory and Cognition 2 (4): 222-34. doi:10.1016/j.jarmac.2013.08.001.

Klein, Stanley B, and Cynthia E Gangi. 2010. “The Multiplicity of Self: Neuropsychological Evidence and Its Implications for the Self as a Construct in Psychological Research." Annals of the New York Academy of Sciences 1191 (1): 1-15. doi:10.1111/j.17496632.2010.05441.x.

Koch, Christof, and Naotsugu Tsuchiya. 2007. "Attention and Consciousness: Two Distinct Brain Processes." Trends in Cognitive Sciences 11 (1): 16-22. doi:10.1016/j.tics.2006.10.012.

Kuhn, T. S. 1962. The Structure of Scientific Revolutions. University of Chicago Press.

Kurth-Nelson, Zeb, Warren Bickel, and A. David Redish. 2012. "A Theoretical Account of Cognitive Effects in Delay Discounting.” European Journal of Neuroscience 35 (7): 1052-64. doi:10.1111/j.1460-9568.2012.08058.x.

Kwan, D, Carl F. Craver, Leonard Green, Joel Myerson, Fuqiang Gao, Sandra E. Black, and R. Shayna Rosenbaum. 2015. "Cueing the Personal Future to Reduce Discounting in Intertemporal Choice: Is Episodic Prospection Necessary?” Hippocampus 25 (4): 43243. doi:10.1002/hipo.22431.

Lefebvre, Germain, Maël Lebreton, Florent Meyniel, Sacha Bourgeois-Gironde, and Stefano Palminteri. 2017. "Behavioural and Neural Characterization of Optimistic Reinforcement Learning." Nature Human Behaviour 1 (4): 67. doi:10.1038/s41562-0170067.

Lehner, Edith, and Arnaud D'Argembeau. 2016. "The Role of Personal Goals in Autonoetic Experience When Imagining Future Events.” Consciousness and Cognition 42: 267-76. doi:10.1016/j.concog.2016.04.002.

Lepre, Christopher J., Hélène Roche, Dennis V. Kent, Sonia Harmand, Rhonda L. Quinn, Jean-Philippe Brugal, Pierre-Jean Texier, Arnaud Lenoble, and Craig S. Feibel. 2011. "An Earlier Origin for the Acheulian." Nature 477 (7362): 82-85. doi:10.1038/nature10372.

Lin, W, Aidan J. Horner, James A. Bisby, and Neil Burgess. 2015. "Medial Prefrontal Cortex: Adding Value to Imagined Scenarios." Journal of Cognitive Neuroscience 27 (10): 1957-67. doi:10.1162/jocn a 0083.

Macleod, Andrew. 2017. Prospection, Well-Being, and Mental Health. Oxford University Press.

MacLeod, Andrew K. 2016. "Prospection, Well-Being and Memory." Memory Studies 9 (3): 266-74. doi:10.1177/1750698016645233.

MacLeod, Andrew K., Philip Tata, John Kentish, and Hanne Jacobsen. 1997. "Retrospective and Prospective Cognitions in Anxiety and Depression." Cognition \& Emotion 11 (4): 467-79. doi:10.1080/026999397379881.

Mahr, Johannes, and Gergely Csibra. 2017. "Why Do We Remember? The Communicative Function of Episodic Memory." Behavioral and Brain Sciences, 1-93. doi:10.1017/S0140525X17000012.

Manning, L. 2016. "Future Mental Time Travel and the Me-Self." In Seeing the Future: Theoretical Perspectives on Future-Oriented Mental Time Travel, edited by K. Michaelian, Stanley B. Klein, and Karl K. Szpunar, 183. Oxford University Press. doi:10.1093/acprof:oso/9780190241537.003.0009.

Marchant, Jo. 2006. “In Search of Lost Time.” Nature 444 (7119): 534-38. doi:10.1038/444534a.

Markus, Hazel, and Paula Nurius. 1986. "Possible Selves." American Psychologist 41 (9): 
954.

Martin-Ordas, Gema. 2016. "With the Future in Mind: Toward a Comprehensive

Understanding of the Evolution of Future-Oriented Cognition." In Seeing the Future:

Theoretical Perspectives on Future-Oriented Mental Time Travel, edited by K.

Michaelian, Stanley B. Klein, and Karl K. Szpunar. New York: Oxford University Press. doi:10.1093/acprof:oso/9780190241537.003.0015.

Martin-Ordas, Gema, Cristina M. Atance, and Julian S. Caza. 2014. "How Do Episodic and Semantic Memory Contribute to Episodic Foresight in Young Children?" Frontiers in Psychology 5 (JUL): 1-11. doi:10.3389/fpsyg.2014.00732.

McBride, Glen. 2012. "Ethology, Evolution, Mind \& Consciousness." Journal of Consciousness Exploration and Research 3 (7): 830-40.

Meacham, John A, and Jeffrey Singer. 1977. "Incentive Effects in Prospective Remembering." The Journal of Psychology 97 (2). Taylor \& Francis: 191-97.

Mesoudi, Alex. 2007. "Has Mental Time Travel Really Affected Human Culture?" Behavioral and Brain Sciences 30 (3). Cambridge University Press: 326-27. doi:10.1017/S0140525X07002129.

Michaelian, K. 2016a. "Against Discontinuism: Mental Time Travel and Our Knowledge of Past and Future Events." In Seeing the Future: Theoretical Perspectives on FutureOriented Mental Time Travel, edited by K. Michaelian, Stanley B. Klein, and Karl K. Szpunar. New York: Oxford University Press. doi:10.1093/acprof:oso/9780190241537.003.0004.

_.2016b. Mental Time Travel: Episodic Memory and Our Knowledge of the Personal Past. MIT Press.

Miller, George A, Eugene Galanter, and Karl H. Pribram. 1960. Plans and the Structure of Behavior. New York: Holt Henry and company.

Miloyan, Beyon, Adam Bulley, and Thomas Suddendorf. 2018. "Anxiety: Here and Beyond." Emotion Review.

Miloyan, Beyon, Nancy A. Pachana, and Thomas Suddendorf. 2014. "The Future Is Here: A Review of Foresight Systems in Anxiety and Depression." Cognition \& Emotion 28 (5): 795-810. doi:10.1080/02699931.2013.863179.

Mischel, W. 1961. "Father-Absence and Delay of Gratification." The Journal of Abnormal and Social Psychology 63 (1): 116-24. doi:10.1037/h0046877.

Nauta, Walle J H. 1971. "The Problem of the Frontal Lobe: A Reinterpretation." Journal of Psychiatric Research 8 (3). Pergamon: 167-87.

Nesse, Randolph M., and George C. Williams. 1994. Why We Get Sick: The New Science of Darwinian Medicine. Vintage.

Noël, Xavier, Nematollah Jaafari, and Antoine Bechara. 2017. "Addictive Behaviors: Why and How Impaired Mental Time Matters?” 235: 219-37. doi:10.1016/bs.pbr.2017.07.011.

O'Connell, Garret, Anastasia Christakou, and Bhismadev Chakrabarti. 2015. "The Role of Simulation in Intertemporal Choices." Frontiers in Neuroscience 9. doi:10.3389/fnins.2015.00094.

Oettingen, Gabriele, A. T. Sevincer, and P. M. Gollwitzer. 2018. The Psychology of Thinking about the Future. Guilford Press.

Okuda, Jiro, Toshikatsu Fujii, Hiroya Ohtake, Takashi Tsukiura, Kazuyo Tanji, Kyoko Suzuki, Ryuta Kawashima, Hiroshi Fukuda, Masatoshi Itoh, and Atsushi Yamadori. 2003. "Thinking of the Future and Past: The Roles of the Frontal Pole and the Medial Temporal Lobes." NeuroImage 19 (4): 1369-80. doi:10.1016/S1053-8119(03)00179-4.

Osvath, Mathias, and Gema Martin-Ordas. 2014. "The Future of Future-Oriented Cognition in Non-Humans: Theory and the Empirical Case of the Great Apes." Philosophical 
Transactions of the Royal Society B: Biological Sciences 369 (1655): 20130486. doi:10.1098/rstb.2013.0486.

Palombo, D. J., M. M. Keane, and M. Verfaellie. 2016. "Using Future Thinking to Reduce Temporal Discounting: Under What Circumstances Are the Medial Temporal Lobes Critical?" Neuropsychologia 89. Elsevier: 437-44.

doi:10.1016/j.neuropsychologia.2016.07.002.

Perrin, Denis. 2016. "Asymmetries in Subjective Time." In Seeing the Future: Theoretical Perspectives on Future-Oriented Mental Time Travel, edited by K. Michaelian, Stanley B. Klein, and Karl K. Szpunar, 39-61. New York: Oxford University Press. doi:10.1093/acprof:oso/9780190241537.003.0003.

Peters, Jan, and Christian Büchel. 2010. "Episodic Future Thinking Reduces Reward Delay Discounting through an Enhancement of Prefrontal-Mediotemporal Interactions." Neuron 66 (1): 138-48. doi:10.1016/j.neuron.2010.03.026.

Pezzulo, Giovanni. 2008. "Coordinating with the Future: The Anticipatory Nature of Representation." Minds and Machines 18 (2): 179-225. doi:10.1007/s11023-008-90955 .

. 2012. "An Active Inference View of Cognitive Control." Frontiers in Psychology 3 (NOV): 2011-12. doi:10.3389/fpsyg.2012.00478.

- 2016. "The Mechanisms and Benefits of a Future-Oriented Brain." In Seeing the Future: Theoretical Perspectives on Future-Oriented Mental Time Travel, edited by K. Michaelian, Stanley B. Klein, and Karl K. Szpunar, 267-84. New York. doi:10.1093/acprof:oso/9780190241537.003.0013.

Pezzulo, Giovanni, Caleb Kemere, and Matthijs A. A. Van Der Meer. 2017. "Internally Generated Hippocampal Sequences as a Vantage Point to Probe Future-Oriented Cognition" 1396 (1): 144-65. doi:10.1111/nyas.13329.

Pezzulo, Giovanni, and Francesco Rigoli. 2011. "The Value of Foresight: How Prospection Affects Decision Making." Frontiers in Neuroscience 5 (JUN). doi:10.3389/fnins.2011.00079.

Pezzulo, Giovanni, Francesco Rigoli, and Karl Friston. 2015. "Active Inference, Homeostatic Regulation and Adaptive Behavioural Control.” Progress in Neurobiology 134: 17-35. doi:10.1016/j.pneurobio.2015.09.001.

Raichle, M. E., A. M. MacLeod, A. Z. Snyder, W. J. Powers, D. A. Gusnard, and G. L. Shulman. 2001. "A Default Mode of Brain Function." Proceedings of the National Academy of Sciences of the United States of America 98 (2): 676-82. doi:10.1073/pnas.98.2.676.

Railton, Peter. 2016. "Morality and Prospection.” In Homo Prospectus. Oxford University Press.

Redshaw, Jonathan. 2014. "Does Metarepresentation Make Human Mental Time Travel Unique?" Wiley Interdisciplinary Reviews: Cognitive Science 5 (5): 519-31. doi:10.1002/wcs. 1308 .

Redshaw, Jonathan, and Adam Bulley. 2018. "Future Thinking in Animals: Capacities and Limitations." In The Psychology of Thinking about the Future, edited by Gabriele Oettingen, A. Timur Sevincer, and Peter M. Gollwitzer. Guilford Press.

Renoult, Louis, Patrick S. R. Davidson, Daniela J. Palombo, Morris Moscovitch, and Brian Levine. 2012. "Personal Semantics: At the Crossroads of Semantic and Episodic Memory." Trends in Cognitive Sciences 16 (11): 550-58. doi:10.1016/j.tics.2012.09.003.

Rescorla, R. A., and A. R. Wagner. 1972. "A Theory of Pavlovian Conditioning: Variations in the Effectiveness of Reinforcement and Nonreinforcement." In Classical Conditioning II: Current Research and Theory, edited by A. H. Black and W. F. 
Prokasy, 64-99. New York: Appleton-Century-Crofts.

Risko, Evan F., and Sam J. Gilbert. 2016. "Cognitive Offloading." Trends in Cognitive Sciences 20 (9): 676-88. doi:10.1016/j.tics.2016.07.002.

Roepke, Ann Marie, and Martin E. P. Seligman. 2015. "Depression and Prospection." British Journal of Clinical Psychology 55 (1): 23-48. doi:10.1111/bjc. 12087.

Russel, S., and P. Norvig. 2009. Artificial Intelligence: A Modern Approach, Third Edition. Prentice Hall.

Schacter, Daniel L., Donna Rose Addis, and Randy L. Buckner. 2007. "Remembering the Past to Imagine the Future: The Prospective Brain." Nature Reviews Neuroscience 8 (9): 657-61. doi:10.1080/08995600802554748.

Schacter, Daniel L., Roland G. Benoit, and Karl K. Szpunar. 2017. "Episodic Future Thinking: Mechanisms and Functions." Current Opinion in Behavioral Sciences 17: 4150. doi:10.1016/j.cobeha.2017.06.002.

Schultz, W., P. Dayan, and P. R. Montague. 1997. "A Neural Substrate of Prediction and Reward.” Science 275 (5306): 1593-99. doi:10.1126/science.275.5306.1593.

Scott-Phillips, Thomas C., Thomas E. Dickins, and Stuart A. West. 2011. "Evolutionary Theory and the Ultimate-Proximate Distinction in the Human Behavioral Sciences." Perspectives on Psychological Science 6 (1): 38-47. doi:10.1177/1745691610393528.

Seth, Anil K. 2014. The Cybernetic Bayesian Brain - from Interoceptive Inference to Sensorimotor Contingencies. Open MIND. Vol. 35. doi:10.15502/9783958570108.

Sharot, Tali, and Neil Garrett. 2016. "Forming Beliefs: Why Valence Matters." Trends in Cognitive Sciences 20 (1): 25-33. doi:10.1016/j.tics.2015.11.002.

Smallwood, J., and Jonathan W. Schooler. 2015. "The Science of Mind Wandering: Empirically Navigating the Stream of Consciousness." Annual Review of Psychology 66 (1): 487-518. doi:10.1146/annurev-psych-010814-015331.

Smallwood, J., Christine Tipper, Kevin Brown, Benjamin Baird, Haakon Engen, Joseph R Michaels, Scott Grafton, and Jonathan W Schooler. 2013. "Escaping the Here and Now: Evidence for a Role of the Default Mode Network in Perceptually Decoupled Thought." NeuroImage 69: 120-25. doi:10.1016/j.neuroimage.2012.12.012.

Solway, Alec, Terry Lohrenz, and P. Read Montague. 2017. "Simulating Future Value in Intertemporal Choice.” Scientific Reports 7 (Sep): 43119. doi:10.1038/srep43119.

Spreng, R. N., and Cheryl L. Grady. 2010. "Patterns of Brain Activity Supporting Autobiographical Memory, Prospection, and Theory of Mind, and Their Relationship to the Default Mode Network." Journal of Cognitive Neuroscience 22 (6): 1112-23. doi:10.1162/jocn.2009.21282.

Sripada, Chandra. 2016. "Imaginative Guidance: A Mind Forever Wandering." In Homo Prospectus, edited by Martin E. P. Seligman, Peter Railton, Roy F. Baumeister, and Chandra Sekhar Sripada. Oxford University Press.

Stevens, Jeffrey R. 2010. "Intertemporal Choice.” In Encyclopedia of Animal Behavior, edited by M. Breed and J. Moore. Oxford: Academic Press. doi:10.1111/j.17461049.2009.00080.x.

Straus, Murray A. 1962. "Deferred Gratification, Social Class, and the Achievement Syndrome." American Sociological Review, 326-35.

Strotz, Robert Henry. 1955. "Myopia and Inconsistency in Dynamic Utility Maximization." The Review of Economic Studies 23 (3): 165-80.

Suddendorf, Thomas. 2010. "Episodic Memory versus Episodic Foresight: Similarities and Differences." Wiley Interdisciplinary Reviews: Cognitive Science 1 (1): 99-107. doi:10.1002/wcs.23.

_. 2013a. "Mental Time Travel: Continuities and Discontinuities." Trends Cogn Sci 17 (4): 151-52. doi:10.1016/j.tics.2013.01.011. 
2013b. The Gap: The Science of What Separates Us from Other Animals. Basic Books.

_ 2017. "The Emergence of Episodic Foresight and Its Consequences." Child Development Perspectives 11 (3): 191-95. doi:10.1111/cdep.12233.

Suddendorf, Thomas, Melissa Brinums, and Kana Imuta. 2016. "Shaping One's Future Self The Development of Deliberate Practice.” In Seeing the Future: Theoretical Perspectives on Future-Oriented Mental Time Travel, edited by K. Michaelian, Stanley B. Klein, and Karl K. Szpunar. New York: Oxford University Press.

Suddendorf, Thomas, and Janie Busby. 2005. "Making Decisions with the Future in Mind: Developmental and Comparative Identification of Mental Time Travel." Learning and Motivation 36 (12): 110-25. doi:10.1111/j.1365-2427.2004.01300.x.

Suddendorf, Thomas, and M. C. Corballis. 1997. "Mental Time Travel and the Evolution of the Human Mind.” Genetic Social and General Psychology Monographs 123 (2): 13367.

. 2007. "The Evolution of Foresight: What Is Mental Time Travel, and Is It Unique to Humans?" Behavioral and Brain Sciences 30 (3): 299-351. doi:10.1017/S0140525X07001975.

Suddendorf, Thomas, and Julie D. Henry. 2013. "Proximate and Ultimate Perspectives on Memory." Journal of Applied Research in Memory and Cognition 2 (4): 246-47. doi:10.1016/j.jarmac.2013.10.005.

Suddendorf, Thomas, and Chris Moore. 2011. "Introduction to the Special Issue: The Development of Episodic Foresight." Cognitive Development 26 (4): 295-98. doi:10.1016/j.cogdev.2011.09.001.

Suddendorf, Thomas, and Jonathan Redshaw. 2013. "The Development of Mental Scenario Building and Episodic Foresight." Annals of the New York Academy of Sciences 1296 (1): 135-53. doi:10.1111/nyas.12189.

Szpunar, Karl K. 2010. "Episodic Future Thought: An Emerging Concept.” Perspectives on Psychological Science 5 (2): 142-62. doi:10.1177/1745691610362350.

Szpunar, Karl K, and Gabriel A. Radvansky. 2015. "Cognitive Approaches to the Study of Episodic Future Thinking.” The Quarterly Journal of Experimental Psychology 218 (December): 1-22. doi:10.1080/17470218.2015.1095213.

Szpunar, Karl K, R. Nathan Spreng, and D. L. Schacter. 2016. "Toward a Taxonomy of Future Thinking." In Seeing the Future: Theoretical Perspectives on Future-Oriented Mental Time Travel, edited by K. Michaelian, Stanley B. Klein, and Karl K. Szpunar, 111:21-35. New York: Oxford University Press.

Szpunar, Karl K, and Endel Tulving. 2011. "Varieties of Future Experience." Predictions in the Brain: Using Our Past to Generate a Future. doi:10.1093/acprof:oso/9780195395518.003.0008.

Terrett, Gill, Amanda Lyons, Julie D. Henry, Clare Ryrie, Thomas Suddendorf, and Peter G. Rendell. 2017. "Acting with the Future in Mind Is Impaired in Long-Term Opiate Users." Psychopharmacology 234 (1). Springer: 99-108. doi:10.1007/s00213-016-44423.

Thom, James M., and Nicola S. Clayton. 2016. "Evolutionary Perspectives on Prospective Cognition.” In Seeing the Future: Theoretical Perspectives on Future-Oriented Mental Time Travel, edited by K. Michaelian, Stanley B. Klein, and Karl K. Szpunar, 287. Oxford University Press. doi:10.1093/acprof:oso/9780190241537.003.0014.

Tinbergen, Niko. 1963. "On Aims and Methods of Ethology." Zeitschrift Für Tierpsychologie 20: 410-33. doi:citeulike-article-id:9870373.

Tolman, Edward Chace. 1920. "Instinct and Purpose." Psychological Review 27 (3): 217. —. 1948. "Cognitive Maps in Rats and Men." Psychological Review 55 (4): 189. 
Tononi, G. 2004. "An Information Integration Theory of Consciousness." BMC Neurosci 5: 42. doi:10.1186/1471-2202-5-42.

Tulving, Endel. 1972. "Episodic and Semantic Memory 1." Organization of Memory. London: Academic 381 (e402): 4.

. 1985. Elements of Episodic Memory. Oxford University Press.
.2002. "Episodic Memory: From Mind to Brain." Annual Review of Psychology 53 (1): 1-25. doi:10.1146/annurev.psych.53.100901.135114.

Varki, Ajit. 2009. "Human Uniqueness and the Denial of Death.” Nature 460 (7256): 684 684. doi:10.1038/460684c.

Viganò, Eleonora. 2017. “Adam Smith's Theory of Prudence Updated with Neuroscientific and Behavioral Evidence." Neuroethics 10 (2): 215-33. doi:10.1007/s12152-017-93329.

Weiler, J, B. Suchan, B. Koch, M. Schwarz, and I. Daum. 2011. "Differential Impairment of Remembering the Past and Imagining Novel Events after Thalamic Lesions." J Cogn Neurosci 23 (10): 3037-51. doi:10.1162/jocn.2011.21633.

Wiener, Norbert. 1948. Cybernetics: Or Control and Communication in the Animal and the Machine. Vol. 25. MIT press.

Wilson, T. D., and D. T. Gilbert. 2005. "Affective Forecasting: Knowing What to Want." Current Directions in Psychological Science 14 (3): 131-34. doi:10.1111/j.09637214.2005.00355.x.

Wolfram, Stephen. 2017. "When Exactly Will the Eclipse Happen? A Multimillenium Tale of Computation." Wolfram Blog. http://blog.stephenwolfram.com/2017/08/whenexactly-will-the-eclipse-happen-a-multimillenium-tale-of-computation/.

Wynn, Thomas, and Frederick L. Coolidge. 2016. "Archeological Insights into Hominin Cognitive Evolution.” Evolutionary Anthropology 25 (4): 200-213. doi:10.1002/evan.21496.

Zapffe, Peter Wessel. 1933. “The Last Messiah (Gisle R. Tangenes, Trans).” Philosophy Now.

Zietsch, Brendan P., Teresa R. de Candia, and Matthew C. Keller. 2015. "Evolutionary Behavioral Genetics." Current Opinion in Behavioral Sciences 2 (April): 73-80. doi:10.1016/j.cobeha.2014.09.005. 